\title{
TESTING OF INTERGRANULAR AND PITTING CORROSION IN SENSITIZED WELDED JOINTS OF AUSTENITIC STAINLESS STEEL
}

\author{
Bore Jegdic ${ }^{*}$, Biljana Bobićl ${ }^{1}$, Milica Bošnjakov, Behar Alić ${ }^{2}$ \\ ${ }^{1}$ Institute for chemistry, technology and metallurgy, ICTM, Belgrade University, \\ Serbia \\ ${ }^{2}$ Institute for metallurgy "Kemal Kapetanović", Zenica, \\ Bosnia and Herzegovina
}

Received 17.05.2017

Accepted 13.06.2017

\begin{abstract}
Pitting corrosion resistance and intergranular corrosion of the austenitic stainless steel X5Cr Ni18-10 were tested on the base metal, heat affected zone and weld metal. Testing of pitting corrosion was performed by the potentiodynamic polarization method, while testing of intergranular corrosion was performed by the method of electrochemical potentiokinetic reactivation with double loop. The base metal was completely resistant to intergranular corrosion, while the heat affected zone showed a slight susceptibility to intergranular corrosion. Indicators of pitting corrosion resistance for the weld metal and the base metal were very similar, but their values are significantly higher than the values for the heat affected zone. This was caused by reduction of the chromium concentration in the grain boundary areas in the heat affected zone, even though the carbon content in the examined stainless steel is low (0.04 wt. $\% \mathrm{C}$ ).
\end{abstract}

Key words: stainless steel, welded joints, pitting corrosion, intergranular corrosion, electrochemical test methods

\section{Introduction}

Intergranular corrosion and pitting corrosion are forms of localized corrosion that often occur in welded joints of austenitic stainless steels. Intergranular corrosion occurs as dissolution of grain boundaries. At slow cooling of welded joints of austenitic stainless steels in the temperature range from 420 to $820^{\circ} \mathrm{C}$, carbides rich in chromium, preferably $\mathrm{M}_{23} \mathrm{C}_{6}$ [1-3], are precipitated. The actual formula of carbide $\mathrm{M}_{23} \mathrm{C}_{6}$ is $(\mathrm{Cr}$,

* Corresponding author: Bore Jegdić, borejegdic@yahoo.com 
$\mathrm{Fe})_{23} \mathrm{C}_{6}$, because some chromium atoms are replaced by iron atoms in chromium carbide [1]. Precipitation of chromium carbides leads to reduction in the chromium concentration at grain boundary areas. This is due to a slow diffusion of chromium in the austenite in the specified temperature range. If the chromium content is less than the content which is necessary for maintaining the protective passive film, the areas near the grain boundaries become sensitized and susceptible to intergranular corrosion. These areas have a higher dissolution rate in comparison to other grain areas. Sensitization occurs most frequently in welded joints, in the heat affected zone (HAZ) which is parallel to the weld metal.

Intergranular corrosion of stainless steels usually occurs in acid solutions, while pitting corrosion often takes place in neutral chloride solutions. During pit formation, an electrochemical corrosion couple is formed between the passive metal surface and active surface inside the pit. The presence of chloride ions prevents repassivation of the metal surface in the bottom of the pit, which rapidly dissolves. During hydrolysis of metal ions at the bottom of the pit, a decrease in $\mathrm{pH}$ value of the solution in the pit occurs [4]. For stainless steels exposed to neutral $0.5 \mathrm{~mol} \mathrm{dm}^{-3} \mathrm{NaCl}$ solutions, the $\mathrm{pH}$ inside the pit was found to be less than 1 [5].

Pitting corrosion of stainless steels in chloride solutions occurs in three distinct stages: nucleation, metastable pit growth and stable pit growth [6]. Before formation of metastable pits the breakdown of the passive film occurs. Only a fraction of pit nucleation act as a pit nuclei for continued growth and formation of metastable pits [6]. After a relatively short time the metastable pits are repassivated. Frankel [7] proposed that metastable pits are repassivated due to a breakdown of the passive film covers and dilution of the local pit environment. Galvele [8] defined the pit propagation process by the localized acidification model due to metal ions hydrolysis. The critical parameters determining whether pits propagate or repassivate depend on the pit depth $(x)$ and current density of anodic dissolution inside the pit $(j)$. For the critical value of the product $x \cdot j$, the $\mathrm{pH}$ value inside pits is lower than $\mathrm{pH}_{\text {crit, }}$ and pits will propagate. Value of pitting potential $E_{\text {pit }}$ is not the pit initiation potential, but the potential at which stable pits can propagate. Development of stable pits is governed by the pit internal chemistry rather than by the state of passive film [6]. Pit nucleation activity is related to the quality of the passive film.

In the case of welded joints, pits are formed more easily at the places of metallurgical heterogeneity. Pits are formed at interfaces of the austenite-ferrite phase in the weld metal of austenitic stainless steels [9]. Certain ferrite content is required in the weld metal in order to prevent the occurrence of so-called hot cracking during solidification of welded joints [9]. The content of chromium in ferrite is high, so that excessive precipitation of ferrite leads to chromium depletion in the austenitic phase of the weld metal.

Pitting corrosion can occur in the heat affected zone (HAZ) at grain boundary areas depleted in chromium. There are only few data on the pitting corrosion tests in the HAZ [10]. The aim of this paper is to examine pitting corrosion resistance in the HAZ of welded joints in an austenitic stainless steel. During solidification of the welded joint, a small reduction in chromium content occurs in the HAZ. This reduction in chromium content is insufficient to cause intergranular corrosion in real operating conditions. In addition to testing of pitting corrosion resistance in the HAZ, the resistance to pitting corrosion in the base metal and the weld metal was also tested. 


\section{Experimental Part}

\section{Material}

Samples of the stainless steel X5CrNi18-10 (6 mm thick) were welded using tungsten inert gas (TIG). Current intensity during welding was $150 \mathrm{~A}$ and argon was used as a shielding gas. The chemical composition of the stainless steel and the used welding electrode (in accordance with EN 12072 [11]) is shown in table 1.

Table 1. Chemical composition of the stainless steel and welding electrode, wt. \%

\begin{tabular}{l|cccccc}
\hline Mark & $\mathrm{C}$ & $\mathrm{Cr}$ & $\mathrm{Ni}$ & $\mathrm{Mo}$ & $\mathrm{Mn}$ & $\mathrm{Si}$ \\
\hline X5CrNi18-10 & 0.04 & 18.8 & 9.5 & 0.22 & 1.2 & 0.34 \\
G19 9 LSi & 0.03 & 20.1 & 9.9 & 0.07 & 1.9 & 0.80 \\
\hline
\end{tabular}

Ferrite content in the weld metal was measured by FERRITSCOPE FER 3. Ferrite number represents the content of ferrite in the weld metal. Measured ferrite number was $9.97 \%$.

Before testing, the samples were grinded with progressively finer grinding paper (from 400 to 1000 grit). The samples were then degreased with ethanol, washed with distilled water and air-dried.

\section{Electrochemical potentiokinetic reactivation with double loop (DL EPR)}

Susceptibility to intergranular corrosion was tested by the method of electrochemical potentiokinetic reactivation with double loop (DL EPR), in accordance with standard ISO 12732 [12].

Intergranular corrosion testing was performed on the base metal and in the heat affected zone (HAZ). The experiments were carried out in a test solution $\left(0.5 \mathrm{~mol} \mathrm{dm}^{-3}\right.$ $\left.\mathrm{H}_{2} \mathrm{SO}_{4}+0.01 \mathrm{~mol} \mathrm{dm}^{-3} \mathrm{KSCN}\right)$ [12]. The thiocyanate is a depassivator that increases the anodic dissolution during the anodic sweep, as well as the grain boundary attack during the reactivation [13]. The sample of tested stainless steel (working electrode) was placed in the electrochemical cell with a reference electrode (saturated calomel electrode, SCE) and an auxiliary electrode (Pt mesh). The sample surface exposed to the test solution was $0.785 \mathrm{~cm}^{2}$. The tests were performed using the potentiostat Biologic SP 200.

The sample was held at the $E_{\text {corr }}$ for $5 \mathrm{~min}$, and then the potential was shifted in the positive direction to the passivation $(+300 \mathrm{mV})$, at $1.67 \mathrm{mV} \mathrm{s}^{-1}$ sweep rate. Immediately after reaching the passivation potential the polarization direction was reversed and the potential of the test sample was returned to the $E_{\text {corr. }}$ If the steel is susceptible to intergranular corrosion, the activation of grain boundaries takes place. The ratio of charge density which is consumed during the reactivation (i.e. during dissolution of the grain boundary areas, $Q_{\mathrm{r}}$ ) and the charge density consumed during the activation (i.e., during the dissolution of grains and the grain boundaries, $Q_{\mathrm{p}}$ ), is the indicator of the stainless steel susceptibility to intergranular corrosion $\left(Q_{\mathrm{r}} / Q_{\mathrm{p}}\right)_{\mathrm{GBA}}$ : 


$$
\left(\frac{Q_{r}}{Q_{p}}\right)_{G B A}=\frac{Q_{r}}{Q_{p} \cdot\left(10^{-3} \cdot \sqrt{2^{G+5}}\right)}
$$

$G$ is the grain size, according to ISO 643 [14].

Stainless steels that are susceptible to intergranular corrosion are also susceptible to stress corrosion cracking, so that the DL EPR method can be used to assess the susceptibility of stainless steels to stress corrosion cracking, according to literature [12].

\section{Potentiodynamic testing of pitting corrosion}

Pitting corrosion testing was carried out by the potentiodynamic polarization method, according to ASTM G 61 [15]. The pitting potential $E_{\text {pit }}$ is defined as the potential corresponding to the anodic current density of $10 \mu \mathrm{A} \mathrm{cm} \mathrm{cm}^{-2}$ in the region of stable pit growth, according to ISO 15158 [16]. At potentials more positive than $E_{\text {pit, }}$, formed pits continue to grow. The potential of metastable pitting $E_{\text {mpit }}$ was also determined. At potentials more positive than $E_{\text {mpit }}$ metastable pits are formed, which after a short period of time are repassivated. There are two forms of metastable pitting (Type I and Type II) [6]. The Type I is distinguished by a slow growth, followed by sudden deaths of the pit, while the Type II displays a sudden increase followed by a smooth decrease. Type I transients seem to be characteristic of metastable pitting of various stainless steels [6].

The value of $E_{\mathrm{pit}}$ or the difference of $E_{\mathrm{pit}}-E_{\text {corr }}$ is the indicator of pitting corrosion resistance of stainless steels [17]. Also, the value of $E_{\text {mpit }}$ or the difference of $E_{\text {mpit }}-E_{\text {corr }}$ can be used as a measure of pitting corrosion resistance [18].

Pitting corrosion resistance of the austenitic stainless steel $\mathrm{X} 5 \mathrm{CrNi18}-10$ was tested in a solution of $0.3 \mathrm{~mol} \mathrm{dm}{ }^{-3} \mathrm{NaCl}+0.1 \mathrm{~mol} \mathrm{dm}^{-3} \mathrm{Na}_{2} \mathrm{SO}_{4}$, at room temperature. The same electrochemical cell and the same potentiostat were used as in the testing of intergranular corrosion. After the stable $E_{\text {corr value was achieved the polarization curves }}$ were recorded at $0.5 \mathrm{mV} \mathrm{s}^{-1}$ sweep rate.

\section{SEM analysis}

A scanning electron microscope JEOL JSM-5800, operated at $20 \mathrm{keV}$, was used to analyze the morphology of the stainless steel surface after testing of pitting and intergranular corrosion. The grain size $\mathrm{G}$, which is required to calculate the sensitization degree of the stainless steel to intergranular corrosion (Equation 1) was determined by SEM. Determination of the grain size in the HAZ as well as on the base metal was performed. In all cases the grain size was G9, according to ISO 643 [14].

\section{Results and Discussion}

\section{Intergranular corrosion}

The results of testing susceptibility to intergranular corrosion are shown in Figure 1. It can be seen that the value of reactivation charge density $Q_{\mathrm{r}}$ is lower on the base metal (Figure 1a) than in the heat affected zone of welded joint (Figure 1b). Susceptibility to intergranular corrosion can be also estimated using the ratio of maximum reactivation current $I_{\mathrm{r}}$ and maximum passivation current $I_{\mathrm{p}}$ (Figure 1). 

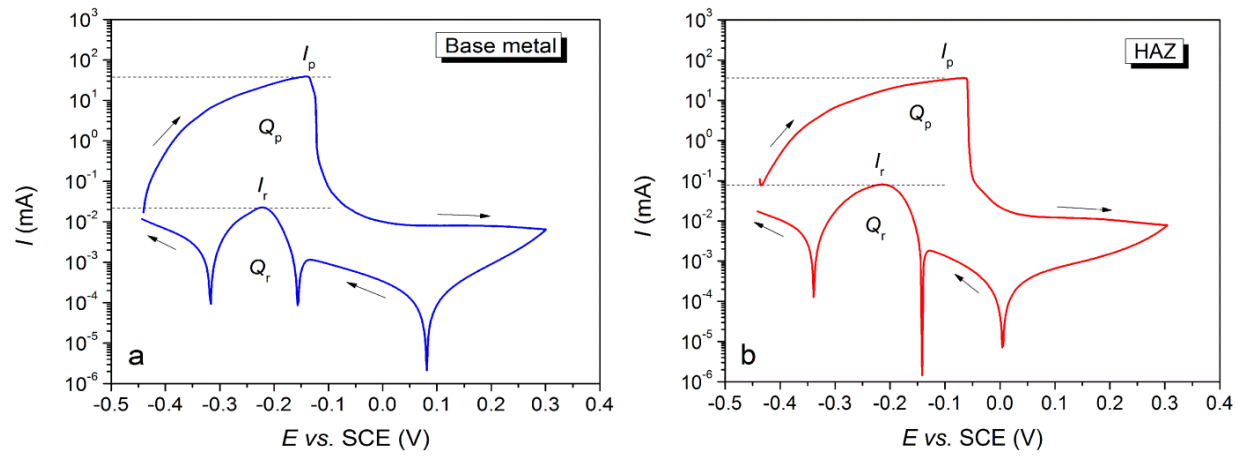

Fig. 1. Results of testing susceptibility to intergranular corrosion: a) base metal and b) heat affected zone

Table 2. Indicators of susceptibility to intergranular corrosion

\begin{tabular}{lcccccc} 
& $\begin{array}{c}E_{\text {corr }} \\
(\mathrm{mV})\end{array}$ & $\begin{array}{c}I_{\mathrm{r}} \\
(\mu \mathrm{A})\end{array}$ & $\begin{array}{c}I_{\mathrm{p}} \\
(\mu \mathrm{A})\end{array}$ & $\begin{array}{c}Q_{\mathrm{r}} \\
(\mathrm{mC})\end{array}$ & $\begin{array}{c}Q_{\mathrm{p}} \\
(\mathrm{mC})\end{array}$ & $\begin{array}{c}\left(Q_{\mathrm{r}} / Q_{\mathrm{p}}\right)_{\mathrm{GBA}} \\
(\%)\end{array}$ \\
\hline Base metal & -440 & 22.6 & 38797 & 0.992 & 2690 & 0.3426 \\
HAZ & -434 & 80.7 & 35839 & 4.940 & 3364 & 1.3643 \\
\hline
\end{tabular}

The quantitative indicators of susceptibility to intergranular corrosion for the tested stainless steel are given in Table 2 . The values of $E_{\text {corr }}$ on the base metal and in the HAZ before the beginning of the DL EPR test are very similar. A very low value of $\left(Q_{\mathrm{r}} / Q_{\mathrm{p}}\right)_{\mathrm{GBA}}$ is obtained for the base metal, indicating that the base metal is not susceptible to intergranular corrosion. Higher value of $\left(Q_{\mathrm{r}} / Q_{\mathrm{p}}\right)_{\mathrm{GBA}}$ indicates that the HAZ is slightly sensitized to intergranular corrosion. The level of sensitization in the HAZ is significantly below the level at which intergranular corrosion can occur in working conditions. If the value $\left(Q_{\mathrm{r}} / Q_{\mathrm{p}}\right)_{\mathrm{GBA}}>5 \%$ it can be expected that intergranular corrosion occurs in the working conditions, according to standard ISO 12732 [12].

SEM micrograph of the austenitic stainless steel surface in the HAZ, after DL EPR test, is shown in Figure 2. Certain dissolution in the grain boundary areas can be seen, as it is shown by the arrow in Figure 2. 


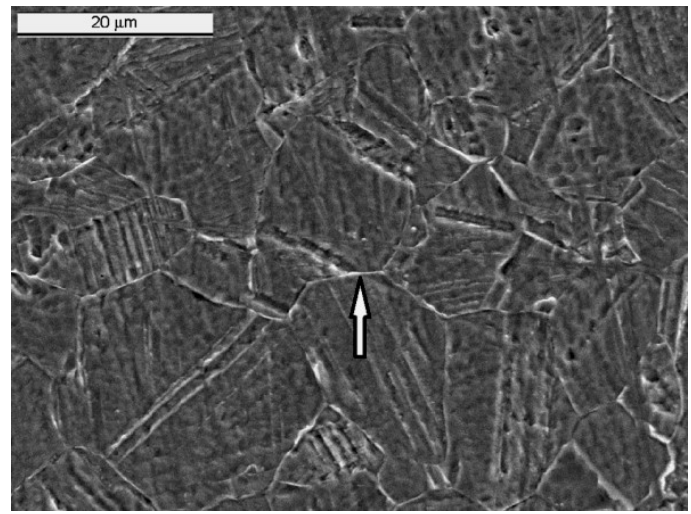

Fig. 2. SEM/SEI micrograph of the austenitic stainless steel surface in the HAZ.

During welding, chromium-rich carbides $\mathrm{M}_{23} \mathrm{C}_{6}$ were precipitated at grain boundaries, causing chromium depletion in the grain boundary areas [19].

\section{Pitting corrosion}

Relatively small current peaks were observed on the polarization curves before reaching the pitting potential $E_{\text {pit. }}$. These peaks correspond to metastable pits formation on the surface of the austenitic stainless steel. Formation of a metastable pit is manifested by gradual current increase to a certain value, and then by sudden drop in current, which indicates repassivation of the metastable pit (Figure 3). The potential at which current density reaches a value greater than $0.02 \mu \mathrm{A} \mathrm{cm}^{-2}$ (in relation to passivation current) was taken as the potential of metastable pits formation $E_{\text {mpit }}$ [18]. At potentials more positive than $E_{\text {mpit }}$, formed metastable pits are repassivated after a short period of time. With further increase of potential, conditions for the stable pits growth are reached. During growth of stable pits (after reaching the pitting potential $E_{\text {pit }}$ ) the current rapidly increases and the pits continue to grow (Figure 3).

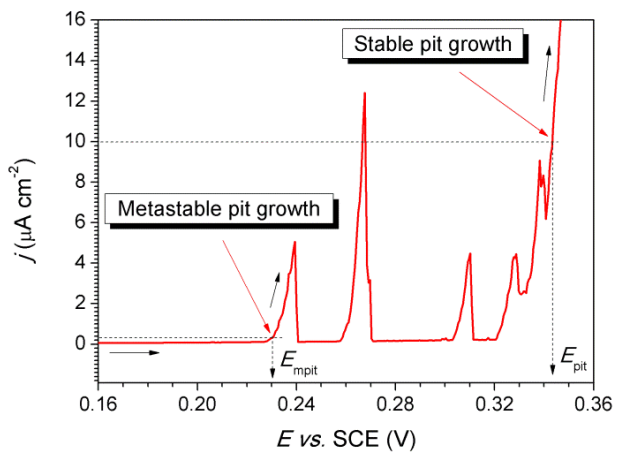

Fig. 3. Polarization curve with metastable and stable pits, on the austenitic stainless steel.

Polarization curves for the base metal, weld metal and HAZ are shown in Figure 4. It may be seen that the values of $E_{\text {mpit }}, E_{\text {pit }}, E_{\text {mpit }}-E_{\text {corr }}$ and $E_{\text {pit }}-E_{\text {corr }}$ are less for the heat affected zone (HAZ) than for the base metal and the weld metal. 

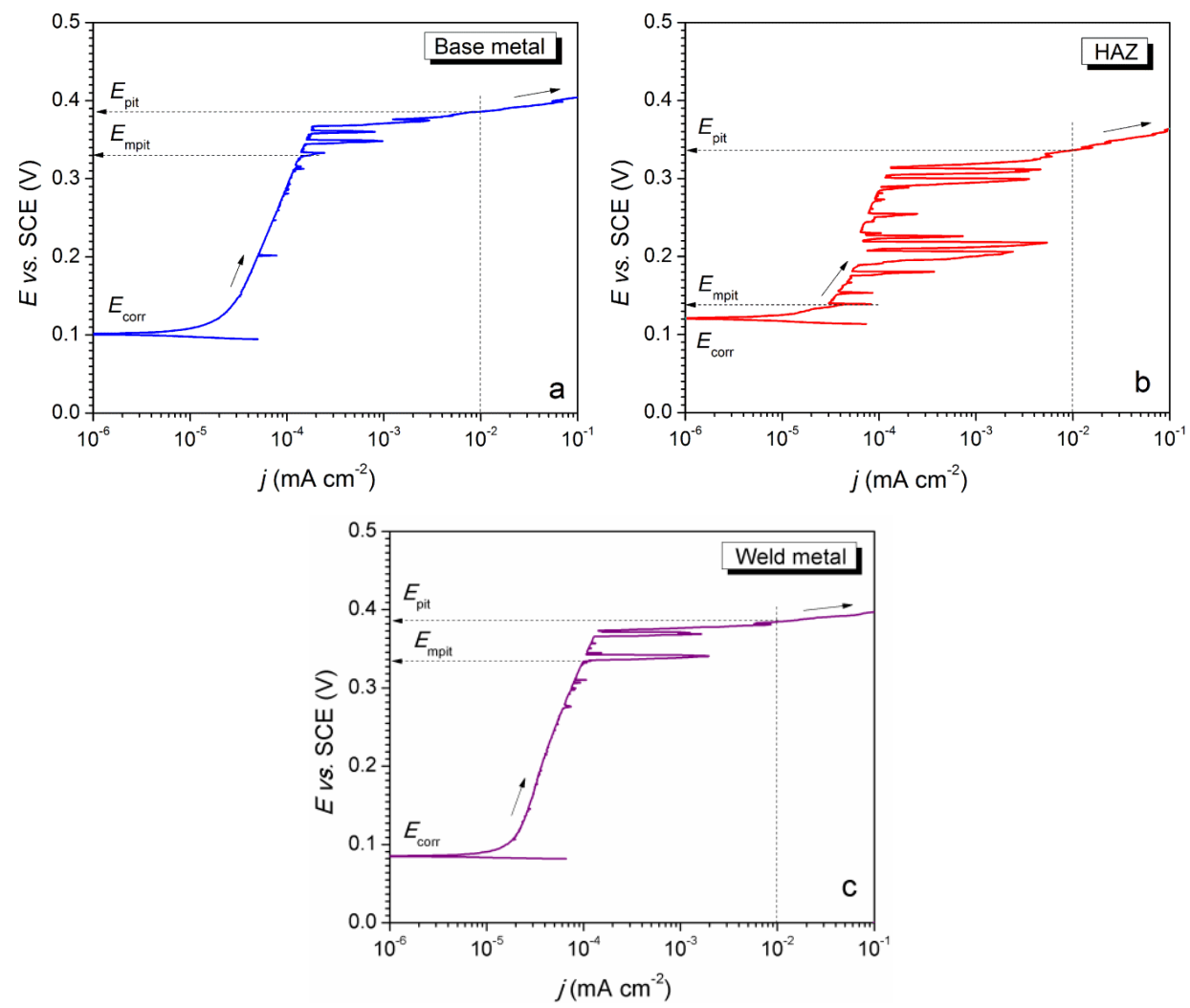

Fig. 4. Polarization curves during pits formation on the austenitic stainless steel: a) base metal, b) HAZ and c) weld metal.

Indicators of pitting corrosion resistance, determined from the experimental polarization curves, are given in Table 3.

Table 3. Indicators of pitting corrosion resistance

\begin{tabular}{lccccc} 
& $\begin{array}{c}E_{\text {corr }} \\
(\mathrm{mV})\end{array}$ & $\begin{array}{c}E_{\text {mpit }} \\
(\mathrm{mV})\end{array}$ & $\begin{array}{c}E_{\text {pit }} \\
(\mathrm{mV})\end{array}$ & $\begin{array}{c}E_{\text {mpit }}-E_{\text {corr }} \\
(\mathrm{mV})\end{array}$ & $\begin{array}{c}E_{\text {pit }}-E_{\text {corr }} \\
(\mathrm{mV})\end{array}$ \\
\hline Base metal & 102 & 332 & 386 & 230 & 284 \\
HAZ & 122 & 138 & 336 & 16 & 214 \\
Weld metal & 84 & 336 & 384 & 252 & 300
\end{tabular}

Values of $E_{\text {mpit }}, E_{\text {pit }}, E_{\text {mpit }}-E_{\text {corr }}$ and $E_{\text {pit }}-E_{\text {corr }}$ for the heat affected zone (HAZ) are less than corresponding values for the base metal and weld metal. Chromium carbides $\mathrm{M}_{23} \mathrm{C}_{6}$ were precipitated at grain boundaries in the HAZ which resulted in sensitization of grain boundary areas. This caused lower pitting corrosion resistance of the HAZ. 
Values of $E_{\text {pit }}$ and $E_{\text {mpit }}$ for the weld metal and the base metal are very similar, although the concentration of chromium in the weld metal is higher than in the base metal (Table 1). The structure of the weld metal is heterogeneous and it consists of austenite and ferrite phase (ferrite content in the weld metal is $\sim 10 \%$ ). Pits are easily formed at the interface ferrite-austenite. In addition, the chromium content in the austenitic phase was decreased during solidification of the weld metal, due to precipitation of ferrite (phase rich in chromium). However, weld metal shows a slightly higher resistance to pitting corrosion than the base metal. The difference of $E_{\text {pit }}-E_{\text {corr }}$ and $E_{\text {mpit }}-E_{\text {corr }}$ for the weld metal is greater than the difference for the base metal.

SEM micrograph of the stainless steel surface after testing pitting corrosion resistance is shown in Figure 5. The pits typical for austenitic stainless steels are formed on the surface.

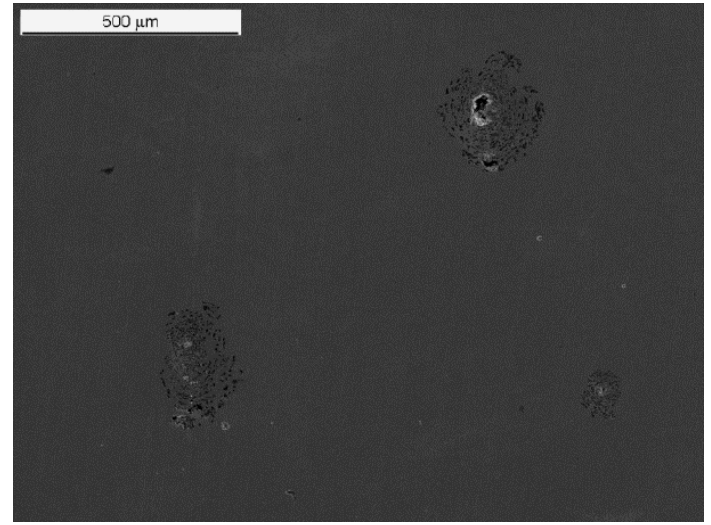

Fig. 5. SEM/SEI micrograph of the stainless steel surface after pitting corrosion testing in the HAZ.

Although the tested stainless steel contains relatively small amount of carbon (0.04 wt. \% C), a mild sensitization in the HAZ occurred during welding. Reduction in the chromium concentration at grain boundary areas in the HAZ resulted with lower pitting corrosion resistance of the tested stainless steel.

\section{Conclusions}

Intergranular and pitting corrosion of the welded joint in the austenitic stainless steel X5CrNi18-10 was tested. The tests were carried out on the base metal, heat affected zone and weld metal.

Testing of intergranular corrosion was performed by the DL EPR method. The base metal is completely resistant to intergranular corrosion, while the heat affected zone is slightly sensitized. However, the level of sensitization in the heat affected zone is lower than the level at which intergranular corrosion occurs in working conditions.

Pitting corrosion resistance was tested by the potentiodynamic polarization method. The heat affected zone exhibits low resistance to pitting corrosion. The resistance of the weld metal and the base metal to pitting corrosion are similar. According to analyzed indicators, the weld metal is more resistant to pitting corrosion than the base metal. 
On the basis of performed tests it can be concluded that chromium carbides $\mathrm{M}_{23} \mathrm{C}_{6}$ were precipitated in the heat affected zone during welding, although the carbon concentration is low ( 0.04 wt. \% in the tested stainless steel). Due to precipitation of chromium carbides at grain boundaries, the chromium concentration in the grain boundary areas was reduced which caused a slight sensitization to intergranular corrosion in the heat affected zone. Although the level of sensitization of the heat affected zone is below the level necessary for the occurrence of intergranular corrosion in real operating conditions, reduction of pitting corrosion resistance in the heat affected zone is evident.

\section{Acknowledgement}

This work was co-financed by the Ministry of Education, Science and Technological Development of Republic of Serbia, through projects TR 34028 and TR 34016.

\section{References}

[1] M. A. Streicher (Revised by J.F. Grubb), Austenitic and Ferritic Stainless Steels, in Uhlig's Corrosion Handbook, third ed., Ed. by R.W. Revie 2011, 657-693.

[2] K.H. Lo, C.H. Shek, J.K.L. Lai: Mater Sci Eng R 65 (2009) 39-104.

[3] K. Kaneko, T. Fukunaga, K. Yamada, N. Nakada, M. Kikuchi, Z. Saghi, J.S. Barnard and P.A. Midgley: Scripta Mater 65 (2011) 509-512.

[4] A.A. Seys, M.J. Brabers and A.A. Van Haute: Corrosion 30 (1974) 47-52.

[5] T. Suzuki, M. Yamabe and Y. Kitamura: Corrosion 29 (1973) 18-22.

[6] J. Soltis: Corros Sci 90 (2015) 5-22.

[7] G.S. Frankel: J Electrochem Soc 145 (6) (1998) 2186-2198.

[8] J.R. Galvele: J Electrochem Soc 123 (4) (1976) 464-474.

[9] J.R. Davis, editor, Corrosion of Weldments, ASM International, Materials Park, Ohio, 2006., p. 5.

[10] H. Yanliang, B. Kinsella, T. Becker: Mater Lett 62 (2008) 1863-1866.

[11] Welding Consumables -Wire Electrodes, Wires and Rods for Arc Welding of Stainless and Heat-resisting Steels - Classification - EN 12072.

[12] Electrochemical potentiokinetic reactivation measurement using the double loop method (based on Čihal's method) - ISO 12732.

[13] D.L. Engelberg, Intergranular Corrosion, in Shreir's Corrosion, Fourth ed., Academic Press, London, 2011, 810-827.

[14] Micrographic determination of the apparent grain size-ISO 643.

[15] Standard Test Method for Conducting Cyclic Potentiodynamic Polarization Measurements for Localized Corrosion Susceptibility of Iron-, Nickel-, or CobaltBased Alloys - ASTM G61.

[16] Method of measuring the pitting potential for stainless steels by potentiodynamic control in sodium chloride solution - ISO 15158.

[17] Standard Test Method for Conducting Cyclic Potentiodynamic Polarization Measurements to Determine the Corrosion Susceptibility of Small Implant Devices - ASTM F2129.

[18] Yuming Tang, Yu Zuo, Jiani Wang, Xuhui Zhao, Ben Niu, Bing Lin: Corros Sci 80 (2014) 111-119.

[19] Mary P. Ryan, David E. Williams, Richard J. Chater, Bernie M. Hutton \& David S. McPhail:Nature, 415 (2002) 770-774. 